\title{
Avaliação do Programa Governamental Conviver: uma questão de cidadania?
}

\author{
Robson Oliveira Marques*, Richard Medeiros Araújo*", Jomária Mata de Lima Alloufa**
}

\section{Resumo}

Este artigo teve como objetivo avaliar, na percepção dos usuários, em que medida as ações do Programa Governamental Conviver contribuem para o exercício de sua cidadania. A pesquisa foi descritiva, delineando-se como um estudo de caso. O universo da pesquisa foi constituído pelos beneficiários do Programa Governamental Conviver cadastrados no Grupo de Convivência Cabelos de Neve. A amostra por tipicidade foi constituída apenas pelos participantes ativos há mais de dez anos. No processo de coleta de dados, utilizou-se a entrevista semiestruturada, apoiando-se em questionamentos básicos, em razão da baixa escolaridade dos entrevistados, adaptado da teoria de Marshall (2002) sobre a construção da cidadania a partir do indivíduo. Os dados foram tratados qualitativamente, por meio da análise de conteúdo proposta por Bardin (1977) denominada de "análise categorial", sendo dividida em três categorias. Quanto aos direitos políticos, embora alguns entrevistados tenham afirmado reconhecer a existência da gerência, demonstraram não conhecer as atribuições desta, nem a possibilidade de avaliar o sistema de atendimento oferecido pelo programa. No tocante aos direitos civis, observou-se que o programa tem estimulado ações que favorecem aos beneficiários acesso aos seus direitos de justiça e às atividades ocupacionais laborais. Com relação aos direitos sociais, constatou-se que o Programa Conviver tem contribuído, em parte, para que seus usuários possam levar uma vida civilizada de acordo com os padrões que prevalecem na sociedade, tendo falhado, contudo, na área da educação.

Palavras-chave: Acontecimentos que mudam a vida. Política social. Estudos de avaliação.

*** Graduada em Pedagogia pela UFRN. Especialista em Pesquisa Educacional pela UFRN. Mestra em Tecnologia Educacional pelo INPE/SJCampos/SP. Doutora em Ciências da Educação pela Université de Paris X Nanterre, França. Professora pesquisadora do Programa de Pós-Graduação em Administração da Universidade Federal do Rio Grande do Norte.

* Graduado em Administração (2007) e Ciências Contábeis (1994) pela Universidade Estadual da Paraíba, com especialização em Contabilidade de Custos para Gestão Contábil/Financeira no processo de Qualidade. Mestre em Administração pelo Programa de Pós-Graduação em Administração da UFRN. Campus Universitário - Bairro Lagoa Nova, CEP: 59072-970 - Natal - RN. E-mail: josirobs@ig.com.br.

** Doutor em Administração pelo PPGA/UFRN.

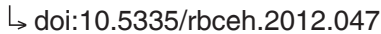




\section{Introdução}

O envelhecimento da humanidade tem inspirado uma série de estudos nas mais diversas áreas do conhecimento, com o objetivo de proporcionar ao idoso uma vida com qualidade e com mais inserção junto à comunidade.

O Instituto Brasileiro de Geografia e Estatística (IBGE) divulgou, em 2007, uma projeção da população brasileira de 1980 até 2050 , a qual passará a ter 183,5 milhões de idosos, representando $85,2 \%$ do seu total.

A Política Nacional do Idoso (BRASIL, 1994), estabelecida pela Lei $\mathrm{n}^{\circ}$ 8.842, de 04 de janeiro de 1994, divulga, em seu art. $3^{\circ}$, que a família, a sociedade e o Estado têm o dever de assegurar ao idoso todos os direitos da cidadania. O Estatuto do Idoso, criado pela Lei $\mathrm{n}^{\circ}$ 10.741 , de 01 de outubro de 2003 (BRASIL, 2003), também garante prioridade absoluta às normas protetoras ao idoso.

O programa governamental avaliado tem o objetivo de proporcionar maior atenção aos idosos, oferecendo-lhes condições de viver em grupos, de modo a ocupar seu tempo ocioso com atividades educacionais, culturais e artísticas. Além disso, o programa visa a promover o engajamento do seu público-alvo com a comunidade, como forma de criar oportunidades de uma melhor interação social e troca de experiências.

No Brasil, as políticas públicas têm se apresentado historicamente insuficientes diante da dimensão dos problemas enfrentados pela maioria da população. De forma mais compensatória do que transformadora, as ações do governo, geralmente, atenuam os efeitos sem combater as raízes do problema, mantendo o mesmo sistema que conserva o quadro de exclusão social existente. Essas afirmativas são encontradas em algumas pesquisas, como as de Assis (2004) e Lebrão (2004), que avaliam os programas governamentais sob a perspectiva da saúde. Outro exemplo é o estudo de Teixeira (2001), o qual trata da questão de programa público que enfoca o empoderamento do idoso no campo da saúde.

Nessa perspectiva, é importante buscar uma compreensão sobre a cidadania dos idosos do grupo Cabelo de Neve do programa municipal em análise. Para tanto, faz-se necessário realizar a avaliação do programa, pois, como destaca Silva (2001), essa etapa constitui uma junção entre as dimensões técnico-metodológica e política, que, necessariamente, articulam-se, para, após as discussões e análises, proceder à emissão de juízos de valor, não sendo um ato neutro, tampouco externo às relações de poder. Diante do exposto, a pergunta que norteia este artigo é: na percepção dos usuários do Grupo de Convivência "Cabelos de Neve", como as ações do Programa Conviver, no município de Campina Grande - PB, contribuem para o exercício da sua cidadania?

A cidadania no contexto dos direitos

Após seis décadas de sua publicação, ocorrida em 1949, o ensaio de Marshall, intitulado "Cidadania e classe social", continua sendo uma referência teórica fundamental quando se pretende refletir sobre a cidadania na sociedade con- 
temporânea. Esse modelo foi escolhido para este trabalho por tratar-se de um modelo clássico e pela influência que ainda exerce à medida que os anos passam. Conforme descreve Souki (2006), as referências ao modelo de Marshall têm-se multiplicado nas pesquisas sobre cidadania nas últimas décadas.

Nesse modelo, os direitos civis e políticos são considerados direitos de primeira geração e os direitos sociais, direitos de segunda geração. (MARSHALL, 2002). O sociólogo inglês diferencia a cidadania daquele status existente na antiguidade e no período feudal, quando ambas as partes encontravam-se fundidas, constituindo, à época, uma distinção de classe e uma forma de medida da desigualdade.

Os direitos civis, conquistados no século XVIII e considerados fundamentais à vida, correspondem aos direitos individuais necessários à liberdade individual, como igualdade perante a lei, direito de ir e vir, direito à propriedade, à vida, de escolher o trabalho, de manifestar o pensamento, de organizar-se, de ter respeitada a inviolabilidade do lar e da correspondência, de não ser preso senão pela autoridade competente e de acordo com as leis, de não ser condenado sem processo legal regular. São os direitos que embasam a concepção liberal clássica.

Já os direitos políticos, alcançados no século XIX, referem-se à participação do cidadão no governo e na sociedade. O exercício desse direito é limitado a uma parcela da população e consiste na capacidade de fazer demonstrações políticas, de votar e ser votado como um membro de um organismo investido da autoridade política ou como um eleitor dos membros de tal organismo. (MARSHALL, 2002). São os direitos políticos que concedem legitimidade à organização política da sociedade.

Com os direitos sociais, as sociedades politicamente organizadas buscam reduzir os excessos de desigualdade produzidos pelo capitalismo e garantir um mínimo de bem-estar para todos. Baseado nessa concepção de Marshall (2002), o cidadão pleno seria aquele titular dos três direitos. Por sua vez, os que possuíssem apenas alguns dos direitos seriam considerados cidadãos incompletos. Por fim, aqueles que não pudessem beneficiar-se de nenhum direito seriam considerados os não cidadãos.

O exercício pleno da cidadania não pretende, em momento algum, impedir a existência da desigualdade do sistema de classes sociais, sendo esta aceitável desde que reconhecida a igualdade da cidadania. (MARSHALL, 2002). Com isso, Marshall pretende destacar que as desigualdades de classes, consideradas características de uma economia de mercado, continuarão existindo, sem que configurem uma contração do exercício da cidadania.

Visão geral do Programa Governamental Conviver

Campina Grande reúne 32.958 pessoas de ambos os sexos, com mais de 60 anos, sendo considerada a segunda cidade da Paraíba com a maior população de idosos, ficando abaixo apenas da capital João Pessoa, com uma população de 48 mil idosos, conforme dados do IBGE. (2007). 
A Secretaria Municipal de Assistência Social (Semas), por meio do Programa Conviver, iniciou, em 1989, o cadastramento dos idosos, a partir de 65 anos, para emissão e posterior recebimento de suas carteiras de identidade, com o objetivo de usufruírem do direito de utilizar gratuitamente os transportes coletivos no município.

Essa primeira ação do Conviver está em conformidade com o artigo 230 da Constituição Federal de 1988, quando prevê que "aos maiores de sessenta e cinco anos é garantida a gratuidade dos transportes coletivos urbanos". Esse direito foi estendido, com a Resolução $n^{\circ}$ 1692/2006 da Agência Nacional dos Transportes Terrestres (ANTT), de 25 de outubro de 2006, para o transporte interestadual gratuito para os idosos que recebem até dois salários-mínimos.

Os idosos foram organizando-se e, juntamente com o Programa Conviver, formaram o primeiro grupo de convivência, que recebeu o nome de "Cabelos de Neve", em homenagem à participante mais idosa.

O programa desenvolve atividades voltadas aos idosos com atuação restrita no município de Campina Grande, oferecendo atividades geriátricas, fisioterápicas, psicológicas, de enfermagem, odontológicas, atividades físicas, culturais, além das sociais.

O Programa Conviver tem como proposta de trabalho: a) incentivar a formação de outros grupos na comunidade; b) realizar atividades culturais e terapias ocupacionais; c) promover atividades na área de saúde e educacionais, inclusive criando condições para a realização de cursos de alfabetização de idosos; d) criar parcerias, no sentido de proporcionar melhores condições de trabalho e e) avaliar, junto aos próprios idosos, o sistema de atendimento que oferece e o desempenho da equipe que executa as ações.

Dando continuidade ao seu processo de expansão, o Programa Conviver inaugurou o Centro Municipal de Convivência do Idoso (CMCI) em 28 de julho de 2000. O CMCI visa a atender os idosos, promovendo o fortalecimento de práticas associativas, produtivas e promocionais, buscando restituir ao idoso o seu sentimento de cidadania. $\mathrm{O}$ centro possui uma equipe multiprofissional composta por assistentes sociais, fisioterapeutas, professores de educação física, geriatras, psicólogas, pedagogas, secretárias, auxiliar de enfermagem e uma equipe de apoio.

\section{Procedimentos metodológicos}

Enquanto fenômeno social, o objeto de pesquisa deste artigo pressupõe a concepção da realidade como socialmente construída, o que implica uma abordagem qualitativa. $\mathrm{O}$ método descritivo foi eleito por se tratar de uma estratégia de pesquisa que busca descrever, sistematicamente, fatos e características presentes em uma determinada população ou área de interesse. (GRESSLER, 2003).

Quanto aos meios de investigação e aos procedimentos técnicos adotados, a pesquisa foi tipificada como de campo e documental. (VERGARA, 2006; GIL, 1999). Procedeu-se a uma revisão bibliográfica, para a fundamentação 
teórico-metodológica, sobre os temas cidadania e avaliação de políticas públicas. Realizou-se, também, uma revisão documental, na medida em que foram analisados documentos internos do Programa Governamental Conviver que possuem relação com o objeto de estudo, tais como: Relatórios de atividades da gerência, Planos de ações e Projeto do Programa. O estudo de caso foi escolhido como método de procedimento neste trabalho, por ser restrito a um programa específico, com caráter de profundidade e detalhamento. (YIN, 2005; TRIVIÑOS, 1987).

O universo da pesquisa foi constituído pelos 34 beneficiários do Programa Conviver cadastrados no Grupo de Convivência "Cabelos de Neve", no bairro Monte Castelo, em Campina Grande - PB. Com a finalidade de aprofundar a investigação, a pesquisa foi realizada junto a um grupo composto apenas pelos participantes ativos há mais de dez anos, correspondendo a um total de 10 idosos. A escolha desse grupo deu-se pelo fato de ter sido o primeiro formado pelo Conviver, reunindo, assim, beneficiários com maior tempo de vivência junto ao programa. Como foi o pioneiro a receber influência das ações desenvolvidas pelo programa, entendeu-se que esses idosos estariam mais habilitados a responder ao questionamento da pesquisa, caracterizando, assim, uma amostragem por tipicidade. (GIL, 1999).

Para a coleta de dados ${ }^{1}$, foi utilizada a entrevista semiestruturada, apoiando-se em questionamentos de fácil compreensão em razão da baixa escolaridade dos entrevistados. Esse instrumento de pesquisa teve como base questões fundamentadas nas três concepções de cidadania descritas por Marshall (2002), podendo tanto o entrevistado como o entrevistador desviar-se para abranger uma ideia ou resposta mais detalhada, explorando, de uma forma flexível e aprofundada, aspectos mais relevantes. As aplicações aconteceram entre os meses de fevereiro e abril de 2010 , sendo as entrevistas gravadas e transcritas com a autorização verbal dos sujeitos investigados. (MARCONI; LAKATOS, 2005).

Neste estudo, foram escolhidos três grupos, baseados em Marshall (2002). $\mathrm{O}$ primeiro contempla as variáveis dos direitos políticos, o segundo, as variáveis dos direitos civis, e o terceiro, as variáveis dos direitos sociais.

No grupo dos direitos políticos, descreve-se a legitimidade do indivíduo de participar do exercício político, como membro de uma entidade investida de autoridade política, ou como um eleitor dos membros dessa entidade.

No segundo grupo, o dos direitos civis, há a descrição da legitimidade necessária para o indivíduo exercer a sua liberdade individual, por meio da garantia dos tribunais de justiça, e a igualdade de direito em participar das ações do Programa.

O terceiro grupo, o dos direitos sociais, refere-se ao direito a um mínimo de bem-estar e segurança, ao direito de participar na herança social e levar a vida de um ser civilizado de acordo com os padrões que prevalecem na sociedade.

Os dados das entrevistas foram tratados por meio da análise de conteúdo, tendo como técnica selecionada a análise categorial (BARDIN, 1977). A partir 
dos três direitos descritos por Marshall (2002), procedeu-se às análises e considerações.

Análise e discussão dos dados: uma leitura sobre os beneficiados pelo Programa Governamental Conviver

A análise e a discussão dos dados são realizadas em quatro momentos. $\mathrm{O}$ primeiro traz o perfil dos idosos investigados; o segundo relaciona a cidadania aos direitos políticos; o penúltimo trata da relação entre a cidadania e o exercício dos direito civis; por fim, apresenta-se a relação entre a cidadania e os direitos sociais.

Para preservar a identidade dos idosos que participaram da pesquisa, durante essa fase, os entrevistados estão nominados de E1 a E10. No que se refere à idade dos sujeitos, verificou-se que oito dos dez entrevistados têm entre 70 e 80 anos e que apenas dois estão com mais de 80 anos. A baixa concentração de idosos mais velhos deve-se, em parte, às complicações de doenças inerentes à faixa etária, as quais dificultam a sua participação no grupo, bem como ao fato de muitos dos que ingressaram no início das atividades já terem falecido. Quanto à variável sexo, constatou-se que dos dez entrevistados seis eram do sexo feminino e quatro do sexo masculino.

Sendo assim, notou-se que a maioria dos idosos que participaram das entrevistas é composta por pessoas do sexo feminino, fato confirmado por meio dos cadastros, nos quais predomina essa população. Nesse sentido, percebe-se que as pessoas idosas que aderem aos programas governamentais são, em sua maioria, do sexo feminino, possivelmen- te pela resistência dos idosos do sexo masculino em participar e pelo fato de a longevidade das mulheres ser maior em comparação à dos homens. Essa última questão parece ser motivada pela maior frequência das mulheres ao médico, com média de uma visita a cada 7,7 meses, enquanto para os homens essa média é de uma visita a cada 16,7 meses. (NERI, 2005).

Com relação à escolaridade, observou-se que, dos dez idosos entrevistados, três são iletrados, quatro possuem o nível fundamental I incompleto, um possui o fundamental completo, um $o$ fundamental II completo e um o superior completo. Notou-se, dessa forma, que, do total de entrevistados na pesquisa, ainda existem três idosos em situação de analfabetismo. Isso conduz à reflexão de que o programa não tem conseguido modificar, com as suas ações sociais, a situação educacional desses idosos durante mais de dez anos de participação, uma vez que permanecem desprovidos de instrução formal.

Quanto à ocupação anterior à aposentadoria dos idosos, observou-se que, dos dez entrevistados, dois exerciam a agricultura, dois eram pedreiros, um era mestre de obras, uma era dona de casa, uma era doméstica, uma era costureira, um era auxiliar de depósito e outra era enfermeira. Esses dados indicam que o programa vem conseguindo atingir um segmento de idosos com baixos níveis de escolaridade, pois mesmo os escolarizados têm baixos níveis de alfabetização e poucos anos de estudos, com exceção apenas de uma entrevistada que possui o curso superior. Além disso, verifica-se 
que os usuários do programa provêm de uma época em que o acesso à educação era mais difícil e precário, sendo um privilégio das classes sociais mais elevadas. (CABRAL, 2002).

Com relação à variável que aborda há quanto tempo o entrevistado participa do programa, verificou-se que três deles participam há quinze anos, outros três há doze anos, dois há onze anos e outros dois há dez anos.

Analisando as entrevistas, constatou-se que, dentre os interesses e as necessidades que levaram os idosos a procurar o Programa Conviver, destacaram-se três: a) o surgimento da depressão após o processo de viuvez; b) a necessidade de lazer; e c) a presença de ociosidade, de ansiedade e sentimento de tristeza no cotidiano. Essas percepções podem ser constatadas nas falas dos entrevistados:

"é porque eu... eu fiquei viúva né, dois anos, aí eu fiquei muito depressiva dois anos... aí eu fui e gostei" (E6).

"é porque o meu marido faleceu... eu fiquei... fiquei viúva, né? Aí eu fiquei muito doente. Fiquei com depressão grande, emagreci, perdi muito peso... fiquei muito, assim, desorientada, sabe?" (E10).

"tinha mais brincadeira, mais divertimento" (E4).

"aí eu, conversando com ele (o vigia), ele tocou no assunto, disse que era vigia daqui do centro de convivência, me disse que aqui tinha jogos, tinha dança. Aí eu disse eu vou olhar, e eu vim olhar, gostei e de primeira eu fiquei logo aquil" (E7). "porque eu não tinha lazer de... não tinha nenhum lazer. Aí procurei frequentar aqui” (E9).

"olhe, é o seguinte: é porque a gente não tem outra diversão, né? Aí, pronto, eu vim pra aqui e aqui eu fui garota primavera, eu fui garçonete, fui florista... aí a gente tá se divertindo e aqui é bom demais" (E8).

"ah, meu filho, eu vou lhe contar. Olha, morreu minha mãe, morreu meu marido, todo ano morria um. [...]. Eu fiquei trancada dentro de casa, uma morta-viva [...], eu não gosto nem de contar que eu fico logo. [...]. Mas quando minha irmã morreu, eu tranquei a porta e não entrava mais ninguém, sou eu mesmo. Fiquei que nem uma morta-viva." (E5).

"eu já estava velho, eu estava com 75 anos mais ou menos, ela (esposa) achava que eu já estava velho e eu sempre insistia trabaIhando, trabalhando, quando foi um dia eu me acidentei. Cheguei em casa, ela quase dÁ em mim, pronto, minha filha, a partiR de hoje eu não vou trabalhar mais. [...]. Quando ela faleceu, aí o negócio ficou ruim pra mim, eu não tinha graça de nada, eu não achava graça" (E3).

\section{Os direitos políticos e a cidadania}

Inicialmente, teve-se a intenção de avaliar como as ações do Programa Conviver têm contribuído para que os idosos participantes exerçam os direitos políticos no município de Campina Grande - PB. Nesse contexto, buscou-se conhecer, na pesquisa representada pela gerência do Programa Conviver, a garantia dos beneficiários em participar de entidades com autoridade política, como eleitores dos membros ou participantes das decisões junto aos coordenadores de tal entidade política. 
Apesar de conhecerem a gerente do Programa, os entrevistados demonstraram ignorar as atribuições dessa gerência, tais como o cadastramento dos participantes, a instrução dos beneficiados sobre o programa, a elaboração de relatórios dos planos de ações para serem encaminhados aos setores competentes etc. Portanto, no contexto dessa variável, parece haver pouco estímulo do programa no que se refere à garantia dos direitos políticos dos idosos no município, já que os beneficiários sequer tinham conhecimento da possibilidade de participarem, junto com a gerência, das avaliações do sistema de atendimento oferecido pelo Conviver, como também da própria equipe que executa as ações, no caso, a gerência. Isso pode ser constatado nas falas transcritas a seguir:

“eu não sei nem dizer” (E8).

"Sim, conheço todas elas. Só a dona [diretora], né" (E7).

"Não, não sei. Eu sei que, do tempo que eu estou aqui, é um pessoal só” (E5).

"A prefeitura escolhe e depois dá baixa nuns, né? Ficam outros" (E8).

As expressões acima evidenciam uma necessidade de esclarecimento quanto à comissão responsável pelo gerenciamento do programa, bem como sobre quais atividades são desempenhadas por ela. Apenas um idoso não soube citar o nome da gerente, porém nenhum participante foi capaz de apontar outros líderes, confundindo a gerência do programa com os demais funcionários com os quais tem contato diário, como professores e vigilantes.
Quando indagados sobre o voto em eleições e sua importância, ficou evidente o exercício pleno desse direito. Para a maioria dos idosos, o ato de votar é relevante e necessário, caracterizando o que Marshall (2002) definiu como consciência política. As transcrições a seguir confirmam o exposto:

"Eu acho legal, né, assim, como diz, eu não sei falar mesmo bem, mas eu acho muito importante a gente ser cidadão, né" (E1).

"É, até com 80 anos, com 100, com 120. Podendo ir votar. É bom" (E2).

"[...] eu toda vida votei, desde os 18 anos eu votei e eu voto, eu voto em quem eu quiser, eu voto sem interesse nenhum" (E3).

"É importante (o voto), eu acho que pelo menos pra mim é importante. Eu acho muito importante, eu tenho paixão por votar" (E4).

De acordo com Marshall (2002), é de fundamental importância que esses direitos possibilitem a participação do indivíduo no exercício do poder político, seja como membro atuante, seja como eleitor dessa autoridade política, que, no contexto da pesquisa, era o Programa Conviver. Em síntese, observou-se que, apesar de conhecerem a gerência do programa, os entrevistados não sabem a forma pela qual ela é estabelecida, nem as suas atribuições, assim como desconhecem a possibilidade de participarem do processo de avaliação do programa, não sendo incentivados a exercer o poder do voto como exercício do poder político e limitando-se a ressaltar a importância do voto. 


\section{Os direitos civis e a cidadania}

Nesse tópico, avaliou-se em que medida as ações do Programa Conviver têm contribuído com os idosos participantes para o exercício de seus direitos civis, descrevendo a liberdade de acesso à gerência e o desenvolvimento de ações no sentido de torná-los conhecedores da Política Nacional do Idoso e do Estatuto do Idoso. Além disso, buscou-se verificar se o programa tem oferecido oportunidade aos seus participantes de exercerem atividades ocupacionais com o objetivo de manter, restaurar e melhorar a capacidade funcional.

Assim, constatou-se, nesta pesquisa, que o Programa Governamental Conviver vem oportunizando aos seus beneficiários o acesso à Política Nacional do Idoso e ao Estatuto do Idoso, por meio de palestras, seminários e esclarecimentos realizados pela própria gerência, conforme transcrições a seguir:

"Eu conheço, mas esqueci o nome [...] diz dos direitos da gente como é. É, eu sou muito esquecida, meu filho. Mas ela fala muito dos direitos da gente" (E2).

"Tem, tem muito. Eu mesmo, em casa, eu tenho uns panfleto, uns cadernozinho que eles fazem, agora mesmo saiu uma do direito da gente [era o Estatuto do Idoso] (E5).

"Mas nós temos... os direitos são vários, né, nós conquistamos muita coisa, nós temos direito a passe grátis, passagem de ônibus, nós temos direito a... a não sofrer violência, não ser lesado por parentes, e a gente correr atrás dos nossos direitos, são muitos os direitos que nós temos agora" (E6).

"O estatuto do idoso já foi lido mais de uma vez... aí tem coisa que muitas vezes a gente não sabe porque é muita coisa, né? [...] a pessoa querendo saber vai e pede que eles (a Gerência) têm aí o Estatuto do Idoso" (E7).

As declarações evidenciam que os beneficiários sabem da existência das leis de proteção aos idosos, mas esse conhecimento é superficial, visto que eles não conseguem entrar em detalhes, fazendo, inclusive, afirmações vagas.

Quanto aos participantes que ainda não possuíam documentos pessoais, observou-se que o programa tem promovido ações para que esses documentos sejam emitidos. Convém salientar que o Conviver tem proporcionado aos idosos atividades ocupacionais, a fim de manter ativa a sua capacidade funcional. Para tanto, oferece práticas de trabalhos manuais e danças folclóricas, que estão previstas nas propostas iniciais de trabalho, contribuindo, assim, na herança social.

[...] a banda de pífano que eu faço parte dela, sou componente da banda de pífanos né... desde quando fundou... a banda de pífanos que vai se apresentar, em muitos cantos, até em outro estado já foi, né? Nessas cidadezinhas aí todas, ela já se apresentou" (E7).

"Trabalhei com planta e barro, fazendo panela de barro... uma parte para gente, a outra a gente dava" (E2).

"aqui tem artesanato, aqui a gente faz flores, aqui faz fuxico, aquelas coisas que faz rodinha de pano, tem muita coisa aqui, muita atividade" (E3).

De acordo com a fala dos entrevistados, o programa inclui a realização de atividades ocupacionais que buscam estimular sua participação e manter sua capacidade funcional ativa, resultando em mais autonomia nas atividades da 
vida diária, em sintonia com o estímulo aos direitos civis, conforme advoga Marshall (2002).

\section{Os direitos sociais e a cidadania}

De acordo com a avaliação feita no tópico anterior, o Programa Conviver tem contribuído para o exercício dos direitos sociais dos idosos. Esses direitos buscam o mínimo de bem-estar econômico e a garantia de mobilidade social, proporcionando a vida de um ser civilizado, de acordo com os padrões que prevalecem na sociedade, por meio do estímulo à saúde, ao lazer e à educação oferecido aos beneficiários.

Nesse sentido, observou-se que o Programa Conviver contempla atividades que estimulam o lazer e a saúde. Quanto ao estímulo à educação, constatou-se deficiência na única atividade realizada pelo programa, conforme as entrevistas com os usuários, visto que atinge apenas os participantes analfabetos, ficando os demais sem incentivo algum nesse universo.

Os respondentes afirmaram, em sua totalidade, que o programa proporciona aos participantes a escolinha de alfabetização, como atividade educacional, o que pode ser verificado nas falas a seguir:

\footnotetext{
"Ah, meu filho, eu participo da escolinha... É ensinar o alfabeto, mas como eu já sei eu não estou indo muito" (E1).

"[...] eles ensinam os idoso a ler, todo ano tem a formatura dos idosos aí." (E6).

"Eu não participo porque... eu tenho a oitava série, e aí não , né... porque é só pra quem é principiante" (E10).
}

Os que não participam acreditam que essa atividade educacional é voltada exclusivamente aos idosos que não sabem ler, o que reforça mais ainda o analfabetismo funcional existente entre os participantes do Programa Conviver. Há, além disso, um equívoco didático dos profissionais educadores responsáveis por essa atividade, na medida em que, segundo alguns idosos, o planejamento das aulas é feito levando em consideração apenas os analfabetos. De acordo com as suas falas, os entrevistados E4, E5 e E7 ficam desassistidos por já serem alfabetizados, demonstrando a necessidade de o programa implementar outras ações que atendam também a esses usuários. Observa-se, ainda, uma evasão por parte de alguns, motivada por problemas de saúde como labirintite, de memória e de visão, o que consta nas afirmações dos entrevistados E1, E2 e E3 descritas abaixo.

"[...] mas ultimamente eu tenho estado meio afastada, porque eu não consigo mais entender, eu tenho labirintite e minha vista tá muito ruim, aí eu já falei para a professora" (E1).

"[...] a professora ensina de um jeito direitinho, né, aí tá na cabeça da gente, quando sai dali a gente se esquece de tudo, pra que eu vou estudar?" (E2).

"Se tem, tem, pô... Eu não participo porque eu me operei desses dois olhos, eu sou meio cego... Eu sou cego mas tem hora que eu vejo tudo [num sentido figurado], mas se eu for pra aula eu não enxergo" (E3).

Com base nessas falas, verifica-se a necessidade de o programa desenvolver diferentes atividades educacionais, de acordo com a realidade e o perfil dos usu- 
ários participantes, para que todos sejam beneficiados. Tal constatação demonstra a ineficiência parcial dessas aulas, comprometendo o objetivo de promover $o$ bem-estar social por meio da educação. (MARSHALL, 2002).

Nessa fase do estudo avaliativo, averiguou-se se o Programa Conviver promove e incentiva a realização de lazer para os seus beneficiários, conforme descrito em sua proposta de trabalho. Nesse contexto, sobre a motivação dos usuários para um convívio social, utilizando atividades de entretenimento e de lazer, os respondentes declararam que o programa promove jogos, danças e algumas viagens, como se confere a seguir:

"[...] jogos [dominó, cartaz] [...] faz umas viagens com o grupo de música, a gente passa um dia, passa uma tarde, tem o lanche" (E1).

"A maior tradição daqui é o forró, você vê o forro, é o tempo todo [...] esses forró. Quando chega gente logo cedinho, já começa o forró, vai até a hora que terminar meio-dia, uma hora, o povo dança aqui... eu gosto de dançar também e brincar, (qual dança?) a dança 0 forró" (E4).

"[...] às vezes tem viagem, passeio, a gente vai à praia, vai à fazenda, passa o dia se divertindo por fora também" (E5).

“Alguma vez eu dou uma dançadinha ali” (E9).

Quando avaliado o contexto da saúde, constatou-se que o Programa Conviver tem promovido ações para conscientizar os seus usuários sobre as medidas profiláticas, por meio de palestras, trabalhando questões relativas à promoção da saúde do idoso e de sua família, além de estimular o autocuidado com vistas ao bem-estar físico, mental e social. Segun- do os respondentes, o programa realiza palestras com o objetivo de abordar algumas doenças, como osteoporose, dengue, problemas odontológicos e de coluna, assim como proporciona consultas com geriatras, incluindo alguns exames:

"É, assim, osteoporose, né, como a gente saber usar o tapete [evitar quedas], ajeitar as coisas do banheiro, cuidados de como sentar, de andar, os movimento que a gente pode fazer. A gente que tem problema de coluna $e$ aí a gente tem que saber essas coisas" (E1).

"[...] saber usar o tapete [evitar quedas], ajeitar as coisas do banheiro, cuidados de como sentar, de andar, os movimento que a gente pode fazer... aqui ensina muitas coisas. Ensina como a gente tem que cuidar pra viver melhor" (E2).

"[...] eu já fiz várias consultas com doutor João Bosco, aqui nesse birô mesmo ele passou muitos exames pra mim. $\mathrm{O}$ ano passado mesmo ele passou um monte de exame sobre os exames da próstata. Lá no posto perto de onde eu moro, lá é meio demorado, aqui eu fiz todos os exames que eu precisava, todos" (E4).

"[...] ah... de todo tipo de saúde porque os meninos sempre estão aqui de... odontologia" (E6).

A "saúde física" foi a categoria relatada com mais frequência, sendo facilmente rememorada pela metade dos participantes. Ficou evidenciado que o aprendizado transmitido tem como plano principal as especificidades fisiológicas da senescência, tais como as doenças ósseas citadas por boa parte dos participantes, em detrimento de outras questões também relevantes que poderiam ser trabalhadas para despertar uma consciência política e cidadã nos envolvidos. 
Segundo as declarações apresentadas, foi possível constatar que o Conviver tem proporcionado atividades relacionadas à área de saúde, item previsto nas propostas iniciais de trabalho do programa, corroborando Marshall (2002), quando afirma que um dos pilares do direito social é permitir ao cidadão levar a vida de acordo com os padrões que prevalecem na sociedade.

\section{Considerações finais}

O primeiro momento deste estudo teve como objetivo identificar em que medida as ações do Programa Conviver têm contribuído para os idosos participantes exercerem os direitos políticos no município de Campina Grande - PB. A busca da consciência de participação desses direitos por parte dos beneficiários era condição básica para a existência de uma relação entre o Programa Conviver e os direitos políticos.

Os beneficiários demonstraram não conhecer as atribuições das atividades da gerência, como o cadastramento dos usuários, a instrução dos participantes sobre o programa, a elaboração de relatórios dos planos de ações para serem encaminhados aos setores competentes etc. Isso sugere pouco estímulo ao exercício dos direitos políticos dos idosos no município, visto que os entrevistados sequer tinham conhecimento da possibilidade de participarem, junto com a gerência, das avaliações do sistema de atendimento oferecido pelo programa e da própria equipe que executa as ações, no caso, a gerência.
Nesse sentido, o Conviver demonstra deficiência no que se refere ao art. $3^{\circ}$ da Lei 8.842, Política Nacional do Idoso, que trata do sistema de informações, pelo fato de não existir um sistema organizado de divulgação dos aspectos políticos do programa junto aos seus usuários.

Quanto à contribuição para o exercício dos direitos civis dos idosos, a liberdade de acesso à gerência e o desenvolvimento de ações no sentido de torná-los conhecedores da Política Nacional do Idoso e do Estatuto do Idoso, constatou-se que o programa utiliza-se de palestras, de seminários e de esclarecimentos realizados pela gerência para alcançar esse objetivo. Isso denota que o programa tem estimulado os direitos civis, pelo fato de os beneficiários estarem tendo acesso aos seus direitos de justiça e às atividades ocupacionais laborais.

Nesse sentido, observou-se que o Programa Conviver realiza atividades que estimulam o lazer e as atividades de saúde, conforme descrito em sua proposta de trabalho. Acerca do estímulo à educação, observou-se deficiência na única atividade realizada pelo programa, visto que atinge apenas os participantes analfabetos, ficando os demais sem incentivo algum. Desse modo, no que se refere aos direitos sociais, o Programa Conviver tem contribuído, em parte, para que seus usuários possam levar uma vida de um ser civilizado, de acordo com os padrões que prevalecem na sociedade.

Constatou-se alta expectativa dos idosos em se manterem ligados ao programa, pois este tem contribuído para dar um novo sentido às suas vidas, em decorrência do isolamento em que se en- 
contravam antes do seu ingresso. Assim, nota-se que o programa assume o papel de protetor para esses idosos, diante de uma sociedade discriminante.

Com base no perfil dos usuários, identificou-se uma série de carências e necessidades do público-alvo, sendo o programa um dos instrumentos para, com base na Política Nacional do Idoso, promover o resgate da sua cidadania, atuando com variadas iniciativas nos campos da saúde, da educação, do lazer, das atividades sociais, dentre outros.

Entende-se que o predomínio de interesse dos idosos nas ações de assistência ocorra em razão do declínio físico provocado pela idade na maioria dessas pessoas, as quais não consideram a educação como algo tão importante. No caso dos entrevistados, a necessidade imediata corresponde ao lazer e à saúde, motivo pelo qual buscaram participar do programa. Constatou-se, por meio de suas falas, que a única atividade educacional realizada pelo programa é a alfabetização, deixando os usuários já alfabetizados "desbeneficiários" de alguma atividade nessa área.

Portanto, com base em Marshall (2002), que classifica o conceito de cidadania em direitos políticos, civis e sociais, conclui-se que o Programa Conviver, na cidade de Campina Grande - PB, não tem contribuído para promover a cidadania plena de seus usuários participantes no grupo de convivência Cabelos de Neve. Com efeito, suas atividades atendem, em parte, aos direitos civis e sociais, porém não contemplam ações que incentivem o exercício dos direitos políticos.
Por fim, com a presente pesquisa, espera-se contribuir com as discussões já existentes e as vindouras sobre a questão da cidadania, para que, mediante sua compreensão, invista-se na melhoria das políticas públicas relacionadas ao tema.

\section{Programme Evaluation Government Conviver: a question of citizenship?}

\section{Abstract}

This article aims to assess the perception of users, such as the actions of the Government Program Living contribute to the exercise of their citizenship. The research was descriptive and a case study. The research was composed of the beneficiaries enrolled in the Government Program Group Living Living Hair Snow, and the sample constituted by the active participants, more than ten years, considered a sample of typicality. In the process of data collection was used semi-structured interview, based on basic questions, due to low education level of respondents, adapted from the theory of Marshall (2002) on the construction of citizenship from the individual. The data were compared qualitatively through content analysis proposed by Bardin (1977) called categorical analysis. The analysis was divided into three categories. As for the Political Rights, some respondents said they recognized the existence of coordination, but on the other hand, demonstrated not know the duties of this coordination, nor the possibility that they may evaluate the system of care offered by the program. On Civil Rights noted that the Program has stimulated actions that favor, the beneficiaries, their rights of access to justice and access to occupational work activities. Regarding Social Rights, noted that the Living Program has contributed in part to allow your users to lead a life of a civilized being 
according to the standards that prevail in society, failing in education

Keywords: Life change events. Social policy. Evaluation studies.

\section{Referências}

AGÊNCIA NACIONAL DE TRANSPORTES TERRESTRES. Resolução n $\square$ 1692/2006. Regulamenta o transporte gratuito para idosos. Diário Oficial da União, Brasília, DF, 25 out. 2006. Seção 3 p. 149.

ASSIS, M. Promoção da saúde e envelhecimento: avaliação de uma experiência no ambulatório do Núcleo de Atenção ao Idoso da UnATI/UERJ. 2004. Tese (Doutorado) Escola Nacional de Saúde Pública, Fundação Oswaldo Cruz, Rio de Janeiro, 2004.

BARDIN, L. Análise de conteúdo. Lisboa: Edições 70, 1977.

BRASIL. Lei n. 8.842 de 1994. Dispõe sobre a Política Nacional do Idoso e dá outras providências. Diário Oficial da União, Brasília, DF, 5 jan. 1994. Seção 1, p. 1.

. Lei n. 10.741 de 2003. Dispõe sobre o Estatuto Nacional do Idoso e dá outras providências. Diário Oficial da União, Brasília, DF, 1 out. 2003. Seção 1, p. 25.

. Constituição da República Federativa do Brasil. Brasília, DF: Senado Federal, 1988.

CABRAL, B. E. S. L. Recriar laços: estudo sobre idosos e grupos de convivência nas classes populares paraibanas. 2002. Tese (Doutorado em Antropologia) - Instituto de Filosofia e Ciências Humanas, Universidade Estadual de Campinas, Campinas, SP, 2002.

CAMARANO, A. A. (Coord.). Como vai o idoso brasileiro? Rio de Janeiro: Ipea, 1999.
CÔRTE, B.; OLIVEIRA, B.; MEDEIROS, S. O Brasil: o que dizem os números sobre a pessoa idosa? In: ENCONTRO NACIONAL DE ESTUDOS POPULACIONAIS - ABEP, 15, 2006, Caxambú, MG. Anais eletrônicos... Caxambú, MG: ABEP, 2006. Disponível em: <http://www.abep.nepo.unicamp.br/ encontro2006/docspdf/ABEP2006_190.pdf>. Acesso em: 13 mar. 2010.

DEMO, P. Cidadania tutelada e cidadania assistida. Campinas, SP: Autores Associados, 1995.

DUMAZEDIER, J. A revolução cultural do tempo livre. São Paulo: Studio Nobel, SESC, 1994.

GIL, A. C. Métodos e técnicas de pesquisa social. São Paulo: Atlas, 1999.

GRESSLER, L. A. Introdução à pesquisa: projetos e relatórios. São Paulo: Edições Loyola, 2003.

INSTITUTO BRASILEIRO DE GEOGRAFIA E ESTATÍSTICA (IBGE). Projeção da população brasileira: 1980-2050. 2007. Disponível em: <http://www.ibge.gov.br/home/ estatistica/populacao/projecao_da_populacao/default.shtm>. Acesso em: 2 jul. 2009.

LEBRÃO, M. L. Condições de saúde. In: LEBRÃO, M. L.; DUARTE, Y. A. O. (Orgs.). Saúde, bem-estar e envelhecimento: Projeto Sabe no município de São Paulo - uma abordagem inicial. Brasília: OPAS, 2003. p. 73-79.

MARCONI, M. A.; LAKATOS, E. M. Fundamentos de metodologia científica. 6 . ed. São Paulo: Atlas, 2005.

MARSHALL, T. H. Cidadania e classe social. 2. ed. Brasília: Senado Federal, Centro de Estudos Estratégicos, Ministério da Ciência e Tecnologia, 2002.

NERI, A. L. As políticas de atendimento aos direitos da pessoa idosa expressas no Estatuto do Idoso. Revista A Terceira Idade, SESC-SP, São Paulo, v. 16, n. 34, p. 7-24, 2005. 
ROESCH, S. M. A. Projetos de estágio e de pesquisa em administração: guias para estágios, trabalhos de conclusão, dissertações e estudos de caso. 3. ed. São Paulo: Atlas, 2005.

CAMPINA GRANDE. Secretaria Municipal de Assistência Social (SEMAS). Programa Conviver: relatório de atividades. Campina Grande, PB, 2008.

Programa Conviver: relatório de atividades. Campina Grande, PB, 2009 .

SILVA, M. O. S. Avaliação de políticas e programas sociais: aspectos conceituais e metodológicos. In: SILVA, Maria Ozanira da Silva (Org.). Avaliação de políticas e programas sociais: teoria e prática. São Paulo: Veras, 2001. p. 54-91.

SOUKI, L. G. A atualidade de T. H. Marshall no estudo da cidadania no Brasil. Civitas: Revista de Ciências Sociais, Porto Alegre, v. 6, n. 1, p. 39-58, jan./jun. 2006.

TEIXEIRA, M. B. Empoderamento de idosos em grupo voltado à promoção da saúde. 2001. Dissertação (Mestrado) - Escola Nacional de Saúde Pública, Fundação Oswaldo Cruz, Rio de Janeiro, 2001.

TRIVINOS, A. N. S. Introdução à pesquisa em Ciências Sociais: a pesquisa qualitativa em educação. São Paulo: Atlas, 1987.

VERGARA, S. C. Métodos de pesquisa em Administração. São Paulo: Atlas, 2006.

YIN, R. K. Estudo de caso: planejamento e métodos. 3. ed. Porto Alegre: Bookman, 2005. 